\title{
WATER POLLUTION
}

\section{Resolving Power of Antipollution Laws}

\author{
P. H. McGAUHEY, M.S.
}

$\mathrm{T}$ WO TYPES of problems confront water pollution control. One concerns the nature of the law itself; the other, legal control of pollution.

The tendency of the citizen who in truth or in fancy is adversely affected by any condition is to cry, "There ought to be a law!" Because we have lots of citizens with lots of interests and lots of real or fancied virtues, we get lots of laws, the variety depending on the factors which influence lawmaking in each State at the particular moment of lawmaking. I shall address my remarks mainly to the problem of the resolving power of antipollution laws.

Presuming (a) that the law established clearly its authority to assert and establish regulations, (b) the morality of the law's intent to protect the virtuous from the sinners, and (c) the sequence of events which constitute enforcement-how can the system fail?

First, if the law is to control pollution, there must be some definition of pollution which can sustain some program of enforcement. At this point we are confronted with two difficulties:

1. How can the intent to protect water quality for various beneficial uses, to define adverse effects, to protect the public health, to preserve resources for future generations, and so on, be translated into a set of thou shalt not's with which to launch an effective program of enforcement?

2. How shall this list of thou shalt not's keep pace with the inventiveness of man, anticipating in advance what wastes each of the 2,000 new

Mr. McGauhey is professor of public health engineering and professor of sanitary engineering, University of California, Berkeley, and director of the university's sanitary engineering research laboratory. industrial products introduced annually may impose?

The solution usually attempted in setting up the law is that the agency required to enforce pollution control "shall establish standards." Now I contend that man tends to set standards, for the control of anything he seeks to control, by one great egg-laying effort, following which enforcement of compliance with standards can be based, he assumes, on simple measurements that compare the dimensions of the pollutant with the size of the egg. The hitch lies not only in the inability of standards to reflect realistically the range of pollutants to be controlled by comparison with standards but also in the tendency for standards to become sacred with antiquity and so acquire validity per se without relation to current fact.

On both these points it is notable that most of our water quality standards relate to the products of organic life and the natural cycle of degradation of dead organic matter. Without depreciating in any way the importance of such measures in protecting the public health, I must note that such standards reflect far too narrow a spectrum of pollutants to be realistic in today's urban industrial situation. And while enforcement agencies are continually being equipped with a broader spectrum of standards, they can never keep pace. Both inventiveness and the long time needed to establish standards conspire to keep the resolving power of the law too gross for the needs of pollution control agencies.

To this problem of the resolving power of the law there is no easy answer. Delegating authority to decide in each case injects an infinite variety of individual whims into the situation and leads to such disagreement among enforcers that no jury is likely to find for the public. So 
the need for a "standard whim" replaces the need for a standard measure.

The problem of framing legislation which will be continuously meaningful and in ascribing pertinence to past court decisions is further complicated by the changing goals of pollution control. Historically, we have experienced three waves of sentiment for pollution control legislation. The first was simply for the protection of the public health-to keep people from getting sick. Later, the concept of health was expanded to include offenses to sight and smell. The next concern was for water quality considerations not strictly related to health, such as irrigation, industrial, and recreational water supplies. Currently, social goals of society have been added to health and beneficial uses. These goals are manifested in a concern for recreational and esthetic values, for aquatic life, for resource conservation, and for clean water per se. While it might be argued that nostalgia for pioneer days ill becomes the urban, industrial, agricultural economy of 1963 , social goals can- not be ignored in considering the legal problems in environmental health.

Another difficulty derives from the increasingly multiple and intensive use of water resources. If we take, for example, all the fresh water from a stream and return only waste water, pollution exists where it may not have existed before when dilution was greater. The same may be said of ground water supplies. So the very concept of water resources development for the beneficial use of mankind is generating a whole spectrum of current problems in the control of water pollution, each aggravated by the questions of standards and omniscience.

How can legislation be formulated which is broad enough to meet the needs of today and elastic enough to meet the needs of the future, both in its concept of the public good and in the resolving power that makes it enforceable either by administrative procedure or by the courts? This is the major problem in water pollution control today. 